\title{
Sindrom postintenzivne skrbi \\ Post-intensive care syndrome
}

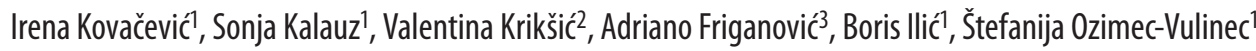

'Zdravstveno veleučilište, Mlinarska 38, 10000 Zagreb, Hrvatska

Applied Health Studies, Mlinarska 38, 10000 Zagreb, Croatia

2Ustanova za zdravstvenu njegu „Domnius”, Jaruščica 9e, 10000 Zagreb, Hrvatska

Health Care Institution “Domnius", Jaruščica 9e, 10000 Zagreb, Croatia

${ }^{3}$ Klinički bolnički centar Zagreb, Kišpatićeva 12, 10000 Zagreb, Hrvatska

University Hospital Center Zagreb,Kišpatićeva 12, 10000 Zagreb, Croatia

Sažetak

Pozadina: Sindrom postintenzivne skrbi (engl. PICS-post-intenzive care syndrome) definira se kao pogoršanje kognitivnih, psihičkih i fizičkih funkcija kod bolesnika koji su preboljeli bolesti s visokim stupnjem smrtnog ishoda u jedinici intenzivnog liječenja (JIL). Precizna prevalencija sindroma je nepoznata: prema publiciranim rezultatima procjenjuje se da se kod jedne četvrtine do jedne polovine preživjelih verificira postojanje nekih od navedenih smetnji.

Cilj: Cilj je preglednog članka iznaći zaključke provedenog empirijskog istraživanja koje istražuje učestalost kognitivnih, psihičkih i fizičkih simptoma u bolesnika nakon otpuštanja iz jedinice intenzivnog liječenja. Istraživanje je trostupanjsko te se ispituju pokazatelji sindroma PICS-a, koji su čimbenici rizika povezani s povećanom incidencijom nastanka sindroma postintenzivne skrbi, i ispitati koje metode i terapijski postupci smanjuju rizik u nastanku PICS-a.

Rezultati: Simptomi su sindroma postintenzivne skrbi slabost mišića, slabija pokretljivost, lošija koncentracija, slabljenje memorije, umor, anksioznost i depresivno raspoloženje. Čimbenici rizika nastanka sindroma postintenzivne skrbi neuromuskularni su poremećaji, demencija, psihijatrijske bolesti, JlL-specifični čimbenici, uporaba mehaničke ventilacije, delirij, sepsa i sindrom akutnog respiratornog distresa. Učestalost nastanka PICS-a može se smanjiti uporabom metoda/postupaka koji smanjuju vremensko trajanje sedacije i ubrzavaju ranu fizičku rehabilitaciju.

Zaključak: Sindrom se verificira kad se pronađu novi ili utvrdi postojanje pogoršanja znakova i simptoma jednog ili više od triju organskih sustava: kognitivni, psihički i fizički. Identifikacija svake navedene komponente potvrđuje se testiranjima. Znakovi i simptomi sindroma postintenzivne skrbi mogu se poboljšati tijekom prvih 6 do 12 mjeseci nakon otpuštanja iz jedinice intenzivnog liječenja. Međutim, kod mnogih pacijenata, deficiti perzistiraju godinama. PICS je povezan s nemogućnošću povratka na posao i smanjenom kvalitetom stupnja života, kao i povećanim rizikom od smrti tijekom nekoliko sljedećih godina.

Ključne riječi: sindrom postintenzivne skrbi • kognitivne smetnje • psihičke smetnje • fizičke smetnje • prevencija

Kratki naslov: Sindrom postintenzivne skrbi

\begin{abstract}
Background: Post-intensive care syndrome (PICS) is defined as worsening of cognitive, psychological and physiological functions in patients with critical conditions, treated in the intensive care units (ICU). Despite the fact that the prevalence of the PICS is yet unknown, it is estimated that up to $1 / 4$ to one half of the above-mentioned patients is suffering from some of the issues associated with PICS. Previous neuromuscular disorders, dementia, psychiatric illnesses as well as ICU-specific factors, especially mechanical ventilation, delirium, sepsis and acute respiratory distress syndrome are known as risk factors for occurrence of PICS.
\end{abstract}

Aim/Purpose: The aim of this systematic review is to extract conclusions from empirical data regarding different cognitive, psychological and physiological functions that the patients released from the intensive care units (ICU) are facing. The objective of this review was to determine the signs and symptoms of PICS; to identify any risk factors related to the occurrence of PICS which are present in the ICU; as well as to identify methods and therapeutic procedures that are significant in decreasing the risk for PICS occurrence.

Results: Some of the issues related to PICS include muscular weakness, limited mobility, low concentration, memory loss, fatigue, anxiety and depressive mood. These symptoms can be established by physical examination and tests. Even though the recovery is possible, many of the symptoms last for months or years after the critical condition and treatment in the ICU. Every patient treated in the ICU should undergo a thorough examination and testing for the signs of PICS. PICS is, in most cases, identified after the discovery of new symptoms or progression of current symptoms including one or more affected areas: cognitive, psychological or physical. The identification of each component is verified by testing.

Conclusion: Signs and symptoms of PICS can be improved during the first 6 to 12 months after the discharge from the ICU. However, majority of the patients experience deficits for years later. PICS is commonly related to inability to time -consuming return to work and decreased level of quality of life, also, it appears that mortality rate over the next few years. PICS can be prevented by using strategies that promote reduced sedation and early physical rehabilitation during the ICU-stay. The main goal of appropriate treatment is that cognitive, psychiatric or physical difficulties must be overwhelmed with additional, appropriate instructions to the medical personnel.

Key words: post-intensive care syndrome $\bullet$ cognitive disorders $\bullet$ mental disorders $•$ physical disability $•$ prevention

Running head: Post-intensive care sy. 


\section{[1] Uvod/Introduction}

Poboljšanje stupnja zdravstvene njege u kritično oboljelih pacijenata rezultira povećanjem stupnja preživljavanja. Znatan broj bolesnika poslije liječenja u jedinici za intenzivno liječenje [JIL] navodi postojanje važnih promjena, i to u mentalnom zdravlju, i u fizičkom funkcioniranju. Spomenute promjene svrstavaju se u sindrom postintenzivne skrbi (engl. PICS-post-intensive care syndrome). Mentalno zdravlje članova obitelji bolesnika može biti narušeno, te je u literaturi poznato pod nazivom post -intenzivni obiteljski sindrom (engl. PICS-family). Znatan broj zdravstvenih djelatnika iznalazi da PICS predstavlja pogoršanje funkcija, jedne ili više njih [ kognitivne, psihičke, fizičke] [1] PICS se najčešće verificira neposredno nakon kritične bolesti. Međutim, budući da su simptomi dugotrajni, a stanje neprepoznato, teško je odrediti vrijeme, nakon kritične bolesti, kada se PICS točno razvija. Tijekom godine dana u Sjedinjenim Američkim Državama, u JIL-u se liječi 5,7 milijuna bolesnika, a u oko 4,8 milijuna završetak liječenja je bez komplikacija [2]. lako je nepoznata točna prevalencija među preživjelima, procjenjuje se da kod 25 do 50\% bolesnika nastaje neka disfunkcija iz sklopa sindroma (kognitivne, psihičke ili fizičke)[3]. To su uglavnom bolesnici koji su primljeni u kiruršku jedinicu intenzivnog liječenja (JIL), u stanju šoka i/ili akutnom respiracijskom insuficijencijom, te je bilo potrebno provesti liječenje uporabom suportivnih metoda [ECMO i sl] [4].

\section{[2] Smetnje iz domene postintenzivne skrbi/ Symptoms of post-intensive care syndrome}

\subsection{Psihičke smetnje}

Najčešća je pojava depresije, anksioznosti i posttraumatskog stresnog poremećaja [engl. post traumatic stress disorder] [5,6]. Međunarodna nacionalna baza podataka iznalazi da se u više od 24.000 bolesnika koji su preživjeli poslije provedenog liječenja uporabom suportivnih metoda liječenja, posebice respiracije, verificira simptomatologija iz domene psihijatrijskih poremećaja [anksioznost i/ili depresija], a kod 19\% bolesnika postoji indikacija za uzimanje psihoaktivnih lijekova[5].

\subsection{Kognitivne smetnje}

Poslije provedenog liječenja visokorizičnih bolesti kognitivne smetnje u prosječnim vrijednostima iznalaze se u $25 \%$ preživjelih. Prema rezultatima recentnih studija učestalost iznosi do 78\%[6,8]. Rezultati provedene studije grupe autora [Johns Hopkins University School of Medicine, Baltimore, Maryland, USA], koja je uključila 821 ispitanika iznalazi sljedeće: odmah nakon završena bolničkog liječenja $6 \%$ bolesnika ima kognitivna oštećenja; tri mjeseca nakon otpusta iz JIL-a 40\% bolesnika ima promjene koje su slične u bolesnika s umjerenim traumatskim ozljedama mozga, a $26 \%$ ima promjene koje su slične blagoj demenciji. 12 mjeseci nakon otpusta, kognitivni deficit je i dalje prisutan [6].

\subsection{Fizičke smetnje}

Najčešći oblik tjelesnog oštećenja poslije liječenja u JIL-u pojava je stečene slabosti, čija incidencija iznosi $25 \%$ ili vi- še [7]. Rezultati provedenih istraživanja pokazuju da je $64 \%$ preživjelih u JIL-u imalo problema s pokretljivošću koje je trajalo šest mjeseci[2]. Nadalje, u 73\% ispitanika verificira se postojanje boli srednjeg do teškog stupnja. Kod 25\% ispitanika utvrđuje se potreba za provođenjem metoda zdravstvene njege u većem obimu od 50 sati tjedno. Većini bolesnika pružali su je članovi obitelji.

\section{[3] Čimbenici rizika za razvoj sindroma/Risk factors for development of thesyndrome}

ICU (engl. Intensive Care Unit) - specifični čimbenici (npr. mehanička ventilacija, akutni delirij, sepsa, akutni respiratorni distres sindrom), mogu pojačati već postojeće čimbenike (npr. neuromuskularni poremećaj, demenciju, psihičke bolesti, pridružena bolesna stanja). Povezanost pojedinih kritičnih bolesti (sepsa, sindrom akutnog respiratornog distresa, moždani udar, trauma) i drugih karakteristika sindroma intenzivne skrbi (npr. mirovanje, prekomjerna sedacija, neadekvatno liječenje delirija ili hospitalizacije), nisu do danas u cijelosti ispitani. Čimbenici rizika nastanka sindroma dijele se na: kognitivne, psihičke i fizičke.

\subsection{Kognitivni čimbenici}

Kongitivni su čimbenici: delirij, pogoršanje stupnja postojećeg kognitivnog deficita, sepsa, ARDS, akutna moždana disfunkcija, alkoholizam, moždani udar, hipoksemija (ARDS, srčani zastoj), hipotenzija (sepsa, trauma), hipoglikemija, zatajenje dišnog sustava (prolongirana mehanička ventilacija), KOPB, kongestivno zatajenje srca, kirurgija srca, opstruktivna apneja u snu [8,9].

\subsection{Psihički čimbenici}

Čimbenici rizika za nastanak psihijatrijske bolesti [npr, tjeskoba, depresija, posttraumatski stresni poremećaj] slični su onima za kognitivne [10,11,12]. Za nastanak sindroma rizik povećavaju postojeća anksioznost i depresija, kao i ženski spol, starosna dob <50 godina, niži stupanj obrazovanja, već postojeća invalidnost/nezaposlenost, uživanje alkohola, primjena sedativa i analgezije [13]. Rezultati recentnih studija upućuju da su glukokortikoidi povezani sa smanjenim rizikom nastanka PTSP-a $[14,15]$. Smatra se da je smanjena razina kortizola povezana s razvojem PTSP-a. Postavljena je hipoteza da primjena glukokortikoida tijekom kritičnih bolesti povećava razinu kortizola čime se smanjuje rizik od nastanka razvoja PTSP-a.

\section{[4] Fizički čimbenici rizika nastanka/Physical risk factor for syn. development}

Smanjenje fizičke kondicije i razvoj slabosti tijekom liječenja u JIL-u povezuju se s produženom uporabom mehaničke ventilacije ( $>7$ dana), sepsom, multi-organskim zatajenjem organa [engl. multiorganic system failure] i produljenim trajanjem u horizontalnom položaju $[16,17]$. Rezultati recentnih studija, iznalaze da je stečena slabost JIL povezana s ARDS-om, sindromom sistemskog upalnog odgovora, nereguliranim vrijednostima GUK-a, starijom životnom dobi te kroničnom uporabom vazoaktivnih lijekova i kortikosteroida $[18,19]$. 


\section{[5] Klinička slika sindroma postintenzivne skrbi/Clinical symptoms of the syndrome}

Klinička slika obuhvaća kognitivne, psihijatrijske i tjelesne simptome i znakove koji su prepoznati ili su se pogoršali nedugo nakon završetka liječenja kritične bolesti. Uobičajeni simptomi su: slabost, slabija pokretljivost, slabija koncentracija, povećan umor, anksioznost i depresivno raspoloženje. lako je oporavak moguć, mnogi znakovi i simptomi mogu trajati mjesecima i godinama [20]. Kognitivne smetnje variraju od blagog oštećenja do teškog stupnja; -od suptilnih teškoća u ostvarivanju složenih radnji do znatne nesposobnosti za obavljanje svakodnevnih životnih aktivnosti. U istraživanju koje je uključilo do danas najveći broj ispitanika, a čiji je primarni cilj bilo utvrđivanje kognitivnih posljedica poslije provedenog liječenja kritične bolesti $u$ JIL-u, utvrđeno je da u tri mjeseca poslije provedenog liječenja do $40 \%$ ispitanika ima deficit koji je sličan u pacijenata koji su pretrpjeli umjerenu traumu mozga, a $26 \%$ ima deficit sličan blagoj demenciji [3]. Područja na kojima se bilježi najveća incidencija jesu jesu: pažnja / koncentracija, memorija, brzina mentalnog procesuiranja, izvršne funkcije.

Psihijatrijski morbiditet poslije provedenog liječenja kritične bolesti u JIL-u znatno je povezan sa snižavanjem stupnja kvalitete života, kako za pacijenta, tako i za članove obitelji $[5,21,22,23,24]$.

Poremećaji raspoloženja uključuju anksioznost, depresiju i PTSP. Najčešći simptomi anksioznosti su pretjerana zabrinutost, razdražljivost, nemir i umor. Bolesnici sa simptomima depresije navode postojanje umora, gubitka interesa, slab apetit, osjećaj beznađa i nesanice. Simptomi koji upućuju na postojanje PTSP-a jesu:afektivne i bihevioralne reakcije koji izazivaju pojavu tzv. flashback simptomatologije i teške tjeskobe.

Fizička oštećenja - pacijenti pokazuju znakove i slabosti opće loše mobilnosti [25]. Ovi znakovi i simptomi često uzrokuju smanjenje u aktivnostima svakodnevnog života (npr. sposobnost uzimanja lijekova, obavljanje kućanskih poslova) [26]. Dodatni čimbenici, koji doprinose fizičkoj disfunkciji su kontrakture, smanjenje fiziološke plućne funkcije i pothranjenost.

Kontrakture. Kontrakture zglobova razvijaju se kao komplikacija dugotrajne nepokretnosti. Rezultati recentno publicirane studije koja opisuje učestalost nastanka kontraktura u bolesnika koji su boravili u intenzivnoj njezi 14 ili više dana, iznalazi se da je u $34 \%$ bolesnika nastala kontraktura [27]. Najčešće zahvaćeni zglobovi bili su zglob i gležanj, nakon čega slijede zglobovi kuka i koljena.

Smanjena funkcija pluća. Učinak mehaničke ventilacije na funkciju pluća najznačajnije je istraživano u bolesnika koji su liječeni zbog akutnog respiratornog distres sindroma [ARDS]. Plućne su funkcije, nakon provedenog liječenja ARDS-a, uvriježeno smanjene u trajanju do pet godina. Najčešći deficit je smanjenje ukupnog volumena pluća. $U$ znatnog broja bolesnika plućna funkcija se normalizira 6 mjeseci poslije provedenog liječenja [28].
Pothranjenost. Gubitak tjelesne težine uvriježen je tijekom kritičnih bolesti, posebice u bolesnika koji su bili na mehaničkoj ventilaciji, koji često primaju manje od $60 \%$ svojih dnevnih potreba za energijom [29]. U studiji koja je uključila 109 ARDS preživjelih, utvrđuje se $18 \%$-ni prosječni gubitak tjelesne težine te vremenski period od 12 mjeseci do dosezanja normalnih vrijednosti [30]. Pothranjenost pridonosi i subjektivnom osjećaju slabosti u bolesnika, kao i smanjenju motoričkih kapaciteta. Osim toga, pacijenti koji su ekstubirani nakon dugotrajne uporabe mehaničke ventilacije, imaju i otežano gutanje, što dodatno otežava sposobnost normalnog i adekvatnog uzimanja i unosa hrane.

\section{[6] Prevencija i liječenje/Prevention and treatment}

Najučinkovitija strategija za sprječavanje nastanka sindroma postintenzivne skrbi smanjenje je duljine trajanja sedacije i rana fizička aktivnost te uporaba metoda rehablitacije u JIL-u [31]. Kako bi se smanjila vjerojatnost nastanka postintenzivnog sindroma u kritično bolesnih pacijenata, osobito u bolesnika koji su bili na mehaničkoj ventilaciji, prema rezultatima recentno publiciranih studija preporučljivo je uporabiti metode/postupke, i to [32].Smanjivanje vremena trajanja sedacije, posebice u bolesnika kod kojih su u uporabi metode potpore respiracije [33], poboljšanje kontrole dišnih funkcija, smanjenje mogućnosti nastanka simptoma iz domene delirija [34], rana mobilizacija/vertikalizacija bolesnika u JIL-u [35].

Metode liječenja preporučljivo je uporabiti za svrhe liječenja bolesnika odmah nakon započinjanja liječenja u JIL-u, i to trenutačnu mobilizaciju i uporabu fizijatrijskih metoda liječenja te kvalitativno i kvantitativno smanjenje sedacije bolesnika. Navedene metode/postupci verificirani su za uporabu, a prema rezultatima provedenih studija imaju najviši stupanj znanstvene značajnosti. Navedene metode preporučljivo je uporabiti u prva 72 sata liječenja u JIL-u radi smanjenja rizika za nastanak sindroma [36].

\section{Zaključak/Conclusion}

Opća su obilježja bolesnika sa sindromom postintenzivne skrbi slabost mišića, smanjena pokretljivost, slabija koncentracija, smanjenje stupnja zapamćivanja, povećanje umora, anksioznost i depresivno raspoloženje. lako je oporavak moguć, mnogi od znakova i simptoma mogu trajati mjesecima i godinama poslije završetka liječenja.

PICS je povezan s nemogućnošću pravodobnog povratka na posao i smanjenjem stupnja kvalitete života te je povećan broj faktora rizika od smrtnog ishoda liječenja u budućnosti.

Nastanak PICS-a može se smanjiti uporabom metoda/postupaka smanjene uporabe sredstava za sedaciju i povećanjem uporabe fizijatrijskih metoda liječenja u JIL-u.

\section{Authors declare no conflict of interest}




\section{Literatura/References}

[1] Needham DM, Davidson J, Cohen $\mathrm{H}$, et al. Improving long-term outcomes after discharge from intensive care unit: report from a stakeholders' conference. Crit Care Med 2012; 40:502.

[2] Griffiths J, Hatch RA, Bishop J, et al. An exploration of social and economic outcome and associated health-related quality of life after critical illness in general intensive care unit survivors: a 12-month follow-up study. Crit Care 2013; 17:R100.

[3] Pandharipande PP, Girard TD, Jackson JC, et al. Long-term cognitive impairment after critical illness. N Engl J Med 2013; 369:1306.

[4] Sukantarat KT, Burgess PW, Williamson RC, Brett SJ. Prolonged cognitive dysfunction in survivors of critical illness. Anaesthesia 2005; 60:847.

[5] Wunsch $\mathrm{H}$, Christiansen $\mathrm{CF}$, Johansen MB, et al. Psychiatric diagnoses and psychoactive medication use among nonsurgical critically ill patients receiving mechanical ventilation. JAMA 2014; 311:1133.

[6] Bienvenu OJ, Colantuoni E, Mendez-Tellez PA, et al. Depressive symptoms and impaired physical function after acute lung injury: a 2-year longitudinal study. Am J Respir Crit Care Med 2012; 185:517.

[7] Hermans G, Van Mechelen H, Clerckx B, et al. Acute outcomes and 1-year mortality of intensive care unit-acquired weakness. A cohort study and propensity-matched analysis. Am J Respir Crit Care Med 2014; $190: 410$

[8] Davydow DS, Zatzick D, Hough CL, Katon WJ. In-hospital acute stress symptoms are associated with impairment in cognition 1 year after intensive care unit admission. Ann Am Thorac Soc 2013; 10:450.

[9] Iwashyna TJ, Ely EW, Smith DM, Langa KM. Long-term cognitive impairment and functional disability among survivors of severe sepsis. JAMA 2010; 304:1787.

[10] Mikkelsen ME, Christie JD, Lanken PN, et al. The adult respiratory distress syndrome cognitive outcomes study: long-term neuropsychological function in survivors of acute lung injury. Am J Respir Crit Care Med 2012; 185:1307.

[11] Jackson JC, Archer KR, Bauer R, et al. A prospective investigation of long-term cognitive impairment and psychological distress in moderately versus severely injured trauma intensive care unit survivors without intracranial hemorrhage. J Trauma 2011;71:860.

[12] Adhikari NK, Tansey CM, McAndrews MP, et al. Self-reported depressive symptoms and memory complaints in survivors five years after ARDS. Chest 2011; 140:1484

[13] Jones C, Griffiths RD, Humphris G, Skirrow PM. Memory, delusions, and the development of acute posttraumatic stress disorder-related symptoms after intensive care. Crit Care Med 2001; 29:573.

[14] Schelling G, Stoll C, Kapfhammer HP, et al. The effect of stress doses of hydrocortisone during septic shock on posttraumatic stress disorder and health-related quality of life in survivors. Crit Care Med 1999; 27:2678.

[15] Schelling G, Briegel J, Roozendaal B, et al. The effect of stress doses of hydrocortisone during septic shock on posttraumatic stress disorder in survivors. Biol Psychiatry 2001; 50:978.

[16] Fan E, Dowdy DW, Colantuoni E, et al. Physical complications in acute lung injury survivors: a two-year longitudinal prospective study. Crit Care Med 2014; 42:849.

[17] Needham DM, Wozniak AW, Hough CL, et al. Risk factors for physical impairment after acute lung injury in a national, multicenter study. Am J Respir Crit Care Med 2014; 189:1214.
[18] Iwashyna TJ, Cooke CR, Wunsch H, Kahn JM. Population burden of long-term survivorship after severe sepsis in older Americans. J Am Geriatr Soc 2012; 60:1070.

[19] Heyland DK, Garland A, Bagshaw SM, et al. Recovery after critical illness in patients aged 80 years or older: a multi-center prospective observational cohort study. Intensive Care Med 2015; 41:1911.

[20] Fletcher SN, Kennedy DD, Ghosh IR, et al. Persistent neuromuscular and neurophysiologic abnormalities in long-term survivors of prolonged critical illness. Crit Care Med 2003; 31:1012.

[21] Hopkins RO, Weaver LK, Pope D, et al. Neuropsychological sequelae and impaired health status in survivors of severe acute respiratory distress syndrome. Am J Respir Crit Care Med 1999; 160:50.

[21] Desai SV, Law TJ, Needham DM. Long-term complications of critical care. Crit Care Med 2011; 39:371.

[22] Davydow DS, Gifford JM, Desai SV, et al. Depression in general intensive care unit survivors: a systematic review. Intensive Care Med 2009; 35:796.

[23] Kapfhammer HP, Rothenhäusler HB, Krauseneck T, et al. Posttraumatic stress disorder and health-related quality of life in long-term survivors of acute respiratory distress syndrome. Am J Psychiatry 2004; 161:45.

[24] Iwashyna TJ, Netzer G, Langa KM, Cigolle C. Spurious inferences about long-term outcomes: the case of severe sepsis and geriatric conditions. Am J Respir Crit Care Med 2012; 185:835.

[25] Jackson JC, Pandharipande PP, Girard TD, et al. Depression, post-traumatic stress disorder, and functional disability in the BRAIN-ICU study: a longitudinal cohort study. Lancet Respir Med 2014; 5:369.

[26] Clavet H, Hébert PC, Fergusson D, et al. Joint contracture following prolonged stay in the intensive care unit. CMAJ 2008; 178:691.

[27] Orme J Jr, Romney JS, Hopkins RO, et al. Pulmonary function and health-related quality of life in survivors of acute respiratory distress syndrome. Am J Respir Crit Care Med 2003; 167:690.

[28] Heyland DK, Schroter-Noppe D, Drover JW, et al. Nutrition support in the critical care setting: current practice in canadian ICUs--opportunities for improvement? JPEN J Parenter Enteral Nutr 2003; 27:74.

[29] Herridge MS, Cheung AM, Tansey CM, et al. One-year outcomes in survivors of the acute respiratory distress syndrome. N Engl J Med 2003; 348:683.

[30] Ventilation with lower tidal volumes as compared with traditional tidal volumes for acute lung injury and the acute respiratory distress syndrome. The Acute Respiratory Distress Syndrome Network. N Engl J Med 2000; 342:1301.

[31] Pandharipande P, Banerjee A, McGrane S, Ely EW. Liberation and animation for ventilated ICU patients: the ABCDE bundle for the backend of critical care. Crit Care 2010; 14:157.

[32] Girard TD, Kress JP, Fuchs BD, et al. Efficacy and safety of a paired sedation and ventilator weaning protocol for mechanically ventilated patients in intensive care (Awakening and Breathing Controlled trial): a randomised controlled trial. Lancet 2008; 371:126.

[33] Bergeron N, Dubois MJ, Dumont M, et al. Intensive Care Delirium Screening Checklist: evaluation of a new screening tool. Intensive Care Med 2001; 27:859.

[34] Patel BK, Pohlman AS, Hall JB, Kress JP. Impact of early mobilization on glycemic control and ICU-acquired weakness in critically ill patients who are mechanically ventilated. Chest 2014; 146:583.

[35] Kayambu G, Boots R, Paratz J. Early physical rehabilitation in intensive care patients with sepsis syndromes: a pilot randomised controlled trial. Intensive Care Med 2015; 41:865. 